INTERNATIONAL JOURNAL OF MULTIDISCIPLINARY RESEARCH AND ANALYSis

ISSN(print): 2643-9840, ISSN(online): 2643-9875

Volume 04 Issue 12 December 2021

DOI: 10.47191/ijmra/v4-i12-33, Impact Factor: 6.072

Page No.- 2013-2021

\title{
The Relationship of Aldosterone and the Degree of Obesity in Patients with Type 2 Diabetes Mellitus Associated with Chronic Heart Failure
}

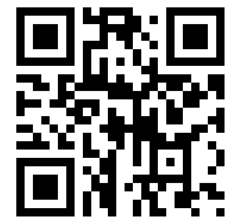

\author{
Sh. K. Yusupova ${ }^{1}$, Z. Yu. Halimova ${ }^{2}$, M.A. Khuzhamberdiev ${ }^{3}$ \\ 'Associate Professor, Ph.D., Head of the Department of Hospital therapy and Endocrinology, Andijan State Medical Institute \\ ${ }^{2}$ Doctor of Medical Sciences, Head of the Department of Neuroendocrinology with pituitary surgery of the Republican Specialized \\ Scientific and Practical Medical Center of the Ministry of Health of the Republic of Uzbekistan named after Academician E.H. \\ Turakulov \\ ${ }^{3}$ Professor, DSc., Head of the Department, Faculty of Therapy, Andijan StateMedical Institute
}

\begin{abstract}
The aim of the study was to study the relationship between aldosterone and the degree of obesity in patients with type 2 diabetes associated with chronic heart failure. The features of metabolic and hormonal disorders were studied in 65 patients with DM2 and CHF, including 29 women and 36 men. The patients were subjected to anthropometric studies (OT, OB, OT/OB, $\mathrm{BMI})$. The interpretation of BMI indicators was carried out in accordance with WHO recommendations. In the studied groups of subjects, lipid fluctuations varied from normal values to their significant deviations in group 3 of patients with grade 2 obesity. The main physiological effects of aldosterone that are important in CHF are 1) sodium and fluid retention (activation of renal aldosterone receptors); 2) activation of aldosterone-dependent; 3) increased excretion of potassium and magnesium; 4) delayed excretion of norepinephrine.So, our results confirm the results of these studies and require further study.In $54.5 \%$ of patients with DM2 and CHF with obesity of the 1st degree and $81.8 \%$ of patients with obesity of the 2 nd degree, an increased level of plasma aldosterone is determined, accompanied by an increased content of renin, $p<0.05$
\end{abstract}

KEYWORDS: Type 2 diabetes mellitus, chronic heart failure, hormones.

\section{INTRODUCTION}

As is known, the main concept of the development of heart failure is the excessive activation of neurohormonal systems, prima rily renin-angiotensin-aldosterone (RAAS) and sympatho-adrenal [1,2]. According to the authors, hyperactivation of RAAS causes the development of atherosclerosis, cardiomyocyte apoptosis, myocardial fibrosis and vascular inflammation $[3,4]$.

Angiotensin II (ATII), renin and aldosterone play a leading role in the development of myocardial fibrosis and apoptosis. Thus, ATII, which is formed in the myocardium under the influence of tissue RAAS, increases the permeability of the endothelium of the coronary arteries, improving the delivery of growth factors to the site of their action, controls the processes of apoptosis, increases the synthesis of mitogens and growth factors involved in the remodeling of the heart, increases the synthesis of cytokines and other neurohormones (aldosterone, vasopressin, endothelin) [5].

According to studies, aldosterone plays a dominant role in the regulation of myocardial tissue processes. Its hyperactivation leads to two main pathogenetic disorders. Firstly, it is one of the mechanisms of atherogenesis - namely, due to endothelial dysfunction, reduced bioavailability of nitric oxide, systemic inflammation, hypercoagulation (stimulation of a plasminogen activator inhibitor) [6,7]. Secondly, the mechanism of progressive myocardial fibrosis and the development of the rigid wall of the left ventricle (LV) is described. This combination of impaired myocardial blood supply and cardiac fibrosis processes becomes the basis for the development of pathological remodeling of the heart with the outcome in chronic heart failure (CHF).

As is known, aldosterone stimulates collagen synthesis by fibroblasts and, by affecting the intracellular balance of electrolytes, contributes to the death of cardiomyocytes. In turn, the activation of fibroblasts leads to myocardial fibrosis, increased rigidity of the LV walls, diastolic dysfunction, impaired transmission of electrical impulses and apoptosis. All these processes stimulate the development of $\mathrm{HF}$, increase the electrical heterogeneity of the myocardium, which underlies the 


\section{The Relationship of Aldosterone and the Degree of Obesity in Patients with Type 2 Diabetes Mellitus Associated with Chronic Heart Failure}

mechanisms of re-entry (re-entry of the pulse) and reduce the threshold for the development of life-threatening ventricular arrhythmias of cardiac activity.

In Pic.1. are shown the potential mechanisms leading to myocardial damage in DM2.

All of the above highlights the relevance of this study.

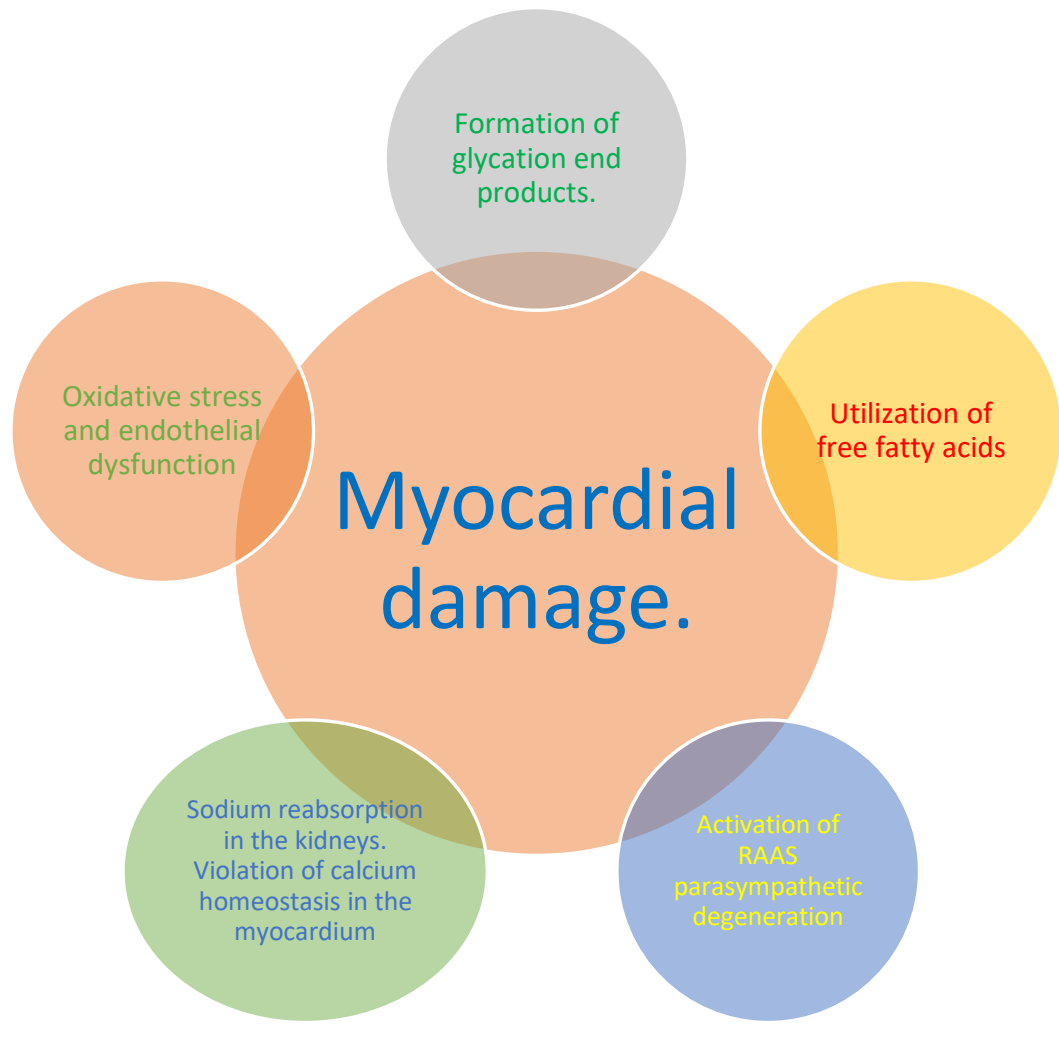

Pic. 1. Potential mechanisms leading to myocardial damage in DM 2. [131].

\section{MATERIAL AND METHODS OF RESEARCH}

The features of metabolic and hormonal disorders were studied in 65 patients with DM2 and CHF, including 29 women and 36 men.

Patients according to the degree of obesity were distributed as follows

1. Group 1 - 21 patients -with DM 2 and CHF with pre-obesity

2. Group 2 - 22 patients with type 2 diabetes and CHF with grade I obesity

3. Group 3 - 22 patients - with DM 2 and CHF with obesity of II degree.

The control group consisted of 20 healthy individuals of the appropriate middle age (10 men and 10 women).

All 65 patients underwent all studies, including general clinical, biochemical (blood sugar, glycemic profile, HbA1c, urea, creatinine, blood electrolytes, lipid spectrum, coagulogram, etc.), hormonal blood tests (C-peptide, insulin, aldosterone, renin, ), ECG, ultrasound of internal organs, , if necessary, patients were referred for additional examination - X-ray, consultation of a cardiologist, neurologist, nephrologist, oculist, and other studies.

The patients were subjected to anthropometric studies (OT, OB, OT/OB, BMI). The interpretation of BMI indicators was carried out in accordance with WHO recommendations: underweight up to $18.5 \mathrm{~kg} / \mathrm{m} 2$, normal weight from 18.5 to $24.9 \mathrm{~kg} / \mathrm{m} 2$, overweight from 25 to $29.9 \mathrm{~kg} / \mathrm{m} 2$, obesity from 30 to $39.9 \mathrm{~kg} / \mathrm{m} 2$.

Statistical calculations were carried out in the Microsoft Windows software environment using Microsoft Excel-2007 and Statistica version 6.0, 2003 software packages. The obtained data are reflected in the dissertation in the form $M \pm m$, where $M$ is the average value of the variation series, $m$ is the standard error of the average value. The reliability of the differences between the independent samples was determined by the Mann-Whitney and Student's. method. 
The Relationship of Aldosterone and the Degree of Obesity in Patients with Type 2 Diabetes Mellitus Associated with Chronic Heart Failure

\section{RESULTS AND DISCUSSION}

Table 1 shows the distribution of patients by gender and age.

Table 1. Distribution of patients by gender, age and by groups (according to WHO).

\begin{tabular}{|l|l|l|l|l|}
\hline Age, years & $\mathbf{1}$ group $(\mathbf{n = 2 1})$ & $\mathbf{2}$ group $(\mathbf{n = 2 2})$ & $\mathbf{3}$ group $(\mathbf{n = 2 2})$ & Over all \\
\hline $16-17$ & - & - & - & - \\
\hline $18-29$ & - & - & - & - \\
\hline $30-44$ & - & - & - & - \\
\hline $45-59$ & $3 / 5$ & $5 / 8$ & $4 / 5$ & $30(12 / 18)$ \\
\hline $60-74$ & $5 / 7$ & $3 / 4$ & $4 / 4$ & $27(12 / 15)$ \\
\hline 75 и & $1 /-$ & $2 /-$ & $2 / 3$ & $8(5 / 3)$ \\
\hline Over all & $\mathbf{2 1 ( 9 / 1 1 )}$ & $\mathbf{2 2 ( 1 0 / 1 2 )}$ & $\mathbf{2 2 ( 1 0 / 1 2 )}$ & $\mathbf{6 5}(\mathbf{2 9 / 3 6 )}$ \\
\hline
\end{tabular}

Note: in the numerator - the number of women, in the denominator - the number of men.

As can be seen from Table 1, patients in the age category from 45 to 59 years prevailed - 30 patients, 12 of them women and 18 men.

Our next step was to study the indicators of anthropometry in patients by groups (Tables 2 and 3 ).

Table 2. Average values WV,HV,WV/HV by groups before treatment.

\begin{tabular}{|c|c|c|c|c|c|c|c|c|c|}
\hline \multirow{2}{*}{ GROUP } & \multicolumn{3}{|c|}{$25,0-29, \mathrm{~kg} / \mathrm{m} 2$} & \multicolumn{3}{|c|}{$30,0-34,9 \mathrm{~kg} / \mathrm{m} 2$} & \multicolumn{3}{|c|}{$35,0-39,9 \mathrm{~kg} / \mathrm{m} 2$} \\
\hline & WV & HV & $\begin{array}{l}\text { WV/ } \\
\text { HV }\end{array}$ & WV & HV & WV/HV & WV & HV & WV/HV \\
\hline 1 group & $\begin{array}{l}85,1 \pm \\
13,8\end{array}$ & $\begin{array}{l}89,9 \pm \\
11,6\end{array}$ & $\begin{array}{l}0,95 \pm \\
0,03\end{array}$ & $\begin{array}{l}87,4 \pm \\
12,4\end{array}$ & $\begin{array}{l}93,7 \pm \\
12,8\end{array}$ & $\begin{array}{l}0,93 \pm \\
0,05\end{array}$ & $\begin{array}{l}105,6 \pm \\
13,3\end{array}$ & $\begin{array}{l}110,4 \\
\pm 13,8\end{array}$ & $\begin{array}{l}0,95 \pm \\
0,07\end{array}$ \\
\hline 2 group & $\begin{array}{l}86,3 \pm \\
11,5\end{array}$ & $\begin{array}{l}88,7 \pm \\
10,9\end{array}$ & $\begin{array}{l}0,97 \pm \\
0,02\end{array}$ & $\begin{array}{l}89,7 \pm \\
14,7\end{array}$ & $\begin{array}{l}94,8 \pm \\
12,8\end{array}$ & $\begin{array}{l}0,94 \pm \\
0,06\end{array}$ & $\begin{array}{l}107,8 \pm \\
12,4\end{array}$ & $\begin{array}{l}111, \quad 9 \\
\pm 12,8\end{array}$ & $\begin{array}{l}0,98 \pm \\
0,06\end{array}$ \\
\hline 3 group & $\begin{array}{l}87,2 \pm \\
11,3\end{array}$ & $\begin{array}{l}89,2 \pm \\
10,9\end{array}$ & $\begin{array}{l}0,97 \pm \\
0,03\end{array}$ & $\begin{array}{l}88,7 \pm \\
11,6\end{array}$ & $\begin{array}{l}95,7 \pm \\
12,9\end{array}$ & $\begin{array}{l}0,92 \pm \\
0,02\end{array}$ & $\begin{array}{l}103,1 \pm \\
12,5\end{array}$ & $\begin{array}{l}112,9 \\
\pm 11,9\end{array}$ & $\begin{array}{l}0,91 \pm \\
0,07\end{array}$ \\
\hline
\end{tabular}

Note: WV - waist volume, HV - hip volume, WV/HV- the index of the ratio of indicators for women is normally $<0.85$, for men it is normally equal to 1 .

As can be seen from Table 2, the average values of WV,HV,WV/HV corresponded to the degree of BMI by group and increased with its increase.

Table 3 shows the distribution of BMI by groups.

Table 3. Average BMI values by group

\begin{tabular}{|c|c|c|c|}
\hline BMI & $25,0-29, \mathrm{~kg} / \mathrm{m} 2$ & $30,0-34,9 \mathrm{~kg} / \mathrm{m} 2$ & $35,0-39,9 \mathrm{~kg} / \mathrm{m} 2$ \\
\hline $\begin{array}{l}\text { Averageval } \\
\text { ue }\end{array}$ & $33,5 \pm 3,8$ & $37,8 \pm 3,2$ & $38,2 \pm 4,6$ \\
\hline Over all & 21 & 22 & 22 \\
\hline
\end{tabular}

Note: $\mathrm{BMI}$ - body mass index

As can be seen from Table 3, the average BMI values for the groups corresponded to the classification of obesity by BMI. Next, we studied the parameters of the lipid spectrum by groups. (table 4) 
The Relationship of Aldosterone and the Degree of Obesity in Patients with Type 2 Diabetes Mellitus Associated with Chronic Heart Failure

Table 4. Average values of the lipid spectrum in the groups.

\begin{tabular}{|l|l|l|l|l|l|}
\hline Indicators & $\mathbf{1}$ group & $\mathbf{2}$ group & $\mathbf{3}$ group & control & normal \\
\hline totalcholesterol & $4,57 \pm 0,17$ & $5,25 \pm 0,25$ & $6,89 \pm 0,18^{*}$ & $4,1 \pm 0,6$ & $\begin{array}{l}3.4-5,2 \\
\text { ммоль/л }\end{array}$ \\
\hline triglycerides & $1,01 \pm 0,11$ & $1,32 \pm 0,14$ & $2,05 \pm 0,08^{*}$ & $0,82 \pm 0,04$ & $\begin{array}{l}\text { до } \\
\text { ммоль/л }\end{array}$ \\
\hline b-lipoproteins & $0,49 \pm 0,07$ & $0,5 \pm 0,03$ & $0,58 \pm 0,01$ & $0,44 \pm 0,03$ & $0,35-0,55$ Ед \\
\hline HDL & $1,31 \pm 0,04$ & $1,08 \pm 0,04^{*}$ & $1,01 \pm 0,03^{*}$ & $1,2 \pm 0,31$ & $\begin{array}{l}> \\
\text { ммоль/л }\end{array}$ \\
\hline LDL & $2,18 \pm 0,14$ & $3,09 \pm 0,16$ & $4,03 \pm 0,07$ & $1,1 \pm 0,26$ & $\begin{array}{l}2,4-5,4 \\
\text { ммоль/л }\end{array}$ \\
\hline
\end{tabular}

Note: * - the reliability of differences with the control group $p<0.05$

As can be seen from Table 4, in the studied groups of subjects, lipid fluctuations varied from normal values to their significant deviations in group 3 of patients with grade 2 obesity.

The main physiological effects of aldosterone that are important in CHF are 1) sodium and fluid retention (activation of renal aldosterone receptors); 2) activation of aldosterone-dependent collagenase (development of myocardial fibrosis and perivascular/ interstitial fibrosis, progression of morphological and functional remodeling of the heart and blood vessels, including coronary); 3 ) increased excretion of potassium and magnesium; 4) delayed excretion of norepinephrine. Each of these mechanisms leads to its own pathogenetic consequences: edema and other clinical signs of CHF; systolic and diastolic LV dysfunction; increased myocardial arrhythmogenicity; peripheral vasoconstriction

Next, we studied the average values of aldosterone by groups (Table 5).

Table 5. The average values of aldosterone and renin in the groups.

\begin{tabular}{|l|l|l|l|l|}
\hline Indicators & Control & Groups & $\mathbf{2}$ groupN=22 & $\begin{array}{l}\text { group } \\
\mathbf{N}=\mathbf{2 2}\end{array}$ \\
\cline { 3 - 5 } & $\begin{array}{l}\mathbf{1} \text { group } \\
\mathbf{N}=\mathbf{2 1}\end{array}$ & $34,4 \pm 5,1$ & $176,3 \pm 19,4^{*}$ & $199,2 \pm 18,1^{*}$ \\
\hline $\begin{array}{l}\text { Aldosteron } \\
\text { epg } \backslash \mathrm{ml}\end{array}$ & $36 \pm 8,1$ & $13 \pm 3,2$ & $42 \pm 6,8^{*}$ & $46 \pm 4,5^{*}$ \\
\hline $\begin{array}{l}\text { ReninmME } \\
\text { /ml }\end{array}$ & $11 \pm 2,1$ & 3 & & \\
\hline
\end{tabular}

Note: * - the reliability of differences with the control group $p<0.05$

As can be seen from Table 5, the levels of aldosterone and renin in 2-3 groups were significantly higher than the upper limit of the lying norm and increased with increasing obesity. . At the same time, it should be noted that the levels of aldosterone and renin in group 1 were within normal limits. Plasma aldosterone and renin levels were significantly elevated in 12 patients of group $2(54.5 \%)$ and in 18 patients of group $2(81.8 \%)$. .

Thus, according to our studies in patients with DM2 associated with CHF, as the degree of BMI increased, plasma levels of aldosterone and renin significantly increased $(p<0.05$.$) .$

According to Russian authors [7],. the level of aldosterone was closely correlated with the content of the sodium-uretic peptide NT-proBNP $(r=0.74, p<0.05)$, as well as the severity of heart failure by SHOCK $(r=0.54, p<0.05)(r=0.54, p<0.05)$ and, therefore, can serve as a predictor of the development of $\mathrm{CHF}$ in obese patients.

Other authors have found that a long history of hypertension, the presence of COPD, obesity and renal dysfunction are independent risk factors for the development of secondary hyperaldosteronism. [8].

So, our results confirm the results of these studies and require further study.

\section{CONCLUSIONS}

1) In $54.5 \%$ of patients with DM2 and CHF with obesity of the 1 st degree and $81.8 \%$ of patients with obesity of the 2 nd degree, an increased level of plasma aldosterone is determined, accompanied by an increased content of renin, $p<0.05$ 
The Relationship of Aldosterone and the Degree of Obesity in Patients with Type 2 Diabetes Mellitus Associated with Chronic Heart Failure

2) In patients with DM2 and CHF with obesity of the 2 nd degree, a significantly higher average level of plasma aldosterone was found compared with patients with obesity of the 1st degree.

\section{REFERENCES}

1) Bogdanov A.R., Derbeneva S.A., Chernyak O. O7., A.A. Bogdanovaidr. Genetic predictors of chronic heart failure in obese patients // Obesity and metabolism. 2019; 16 (1): 39-46 doi: https://doi.org/10.14341/omet9667 Obesityandmetabolism. 2019; 16 (1): 39-46

2) Berezikova E.N. Clinical-genetic and neurohormonal mechanisms of ischemic remodeling, myocardial apoptosis and heart failure: an innovative strategy for personalized diagnosis, prevention and treatment. Dissertation for the degree of Doctor of Medical Sciences. sciences. - Tomsk; 2014. (InRuss.)] Available at: http://docplayer.ru/43228271Berezikova-ekaterinanikolaevna.html. Link active on 04/07/2019

3) Bernardi S, Michelli A, Zuolo G, et al. Update on RAAS Modulation for the Treatment of Diabetic Cardiovascular Disease. // J Diabetes Res. 2016; 2016: 8917578.doi: 10.1155 / 2016/8917578.

4) Arutyunov G.P. CHF therapy. Is the choice of the first drug always deterministic? // Russian medical journal. - 2006. T.14. - No. 2. - C.137-142.

5) Dei Cas A, Khan SS, Butler J, Mentz RJ, A et al. Impact of diabetes on epidemiology, treatment, and outcomes of patients with heart failure. JACC. // Heart failure. 2015; 3 (2): 136- 45. DOI: 10.1016 / j.jchf.2014.08.004

6) Vogt B, Bochud M, Burnier M. The Association of Aldosterone With Obesity-Related Hypertension and the Metabolic Syndrome. SeminNephrol. 2007; 27 (5): 529-537. doi: 10.1016 / j.semnephrol.2007.07.009

7) Bogdanov A.R. Derbeneva S.A.,. Golubeva A. And Aldosterone is a possible predictor of heart failure in obese patients? // Medical portal for doctors.

https:

//umedp.ru/articles/aldosteron_vozmozhnyy_prediktor_serdechnoy_nedostatochnosti_u_bolnykh_ozhireniem.html

8) Vatutin N. T., Shevelyok A. Influence of comorbid conditions on the blood aldosterone level in patients with CHF with preserved left ventricular systolic function // https://doi.org/10.15829/1728-8800-2017-6-92-98 